\title{
LET'S GET OUR DUCKS IN A ROW: NOVEL TOOLS FOR CATCHMENT DIAGNOSIS AND PRIORITISATION OF WATERWAY MANAGEMENT INTERVENTIONS
}

\author{
G. BROWNING \\ Healthy Land and Water, Australia.
}

\begin{abstract}
Water by Design is a capacity-building programme based in Brisbane, Australia, that focuses on waterway health and aims to aid local governments and the development industry in the goal of better managing waterways and also transitioning to water-sensitive cities. Water by Design's survey of the issues affecting waterway health reveals a very broad suite of problems to solve. In short, the majority of these problems can be solved via thorough diagnosis of the catchment including assessing the distribution of hazards, values and needs and a strategic planning framework that can prioritise management actions and resources to maximise potential impact. This paper has identified a number of novel tools to simplify the visualisation and analysis of the problems but still address many competing demands that waterway managers need to consider. The tools are inspired by the medical model for managing health and also the addition of red/green/blue colours to produce multidimensional GIS heat maps to identify critical adjacencies within the catchment. With the plethora of management frameworks available today, it is the memorable ideas that survive and are passed on. To address this issue, careful thought has been placed in the design of these tools to enhance the chances that they are remembered, understood and disseminated.
\end{abstract}

Keywords: colour, hazards, management, needs, opportunity, prioritisation, risk, stormwater, values, waterway.

\section{INTRODUCTION}

Waterway management is complex. There are many competing objectives, and it is very difficult for developers and council to find the best mix of solutions. Current stormwater management policy in Queensland does not recognise this complexity, and new tools are needed. The challenge is to devise a system to represent the complexity but has a relatively simple visualisation so this plan can be easily communicated and implemented. This paper calls for novel approaches for conceptualising waterway health priorities including adopting sound principles from the medical model and colour spectrum analysis. While these may be seen as mere novelties by some in the industry, the ideas have been thoughtfully conceived to visualise the problems in helpful ways and are more likely to be remembered and connect with the reader and then adopted and passed on to create impact.

\subsection{The key issues}

Water by Design (WbD) is a capacity-building programme that is currently reviewing the state of Queensland's Stormwater Quality Regulations. The review [1] has identified the following issues with the current system:

- There is a need to avoid one-dimensional solutions that miss the bigger picture and larger potential

- The catchment is not homogeneous, and there is a need to address spatial variation across the state 
- Need to balance 'values protection' activities with 'values enhancement' activities

- Dollars and resources are limited so there is a need to strategically invest so that it can make the biggest impact

\subsection{Prioritisation framework}

This paper builds on the previous work for assessing the ecological risk and developing a management framework [2]. This framework significantly extends the sphere of responsibility for stormwater managers, and instead of just focusing on a number of parameters (e.g. sediment and nutrients), there are many more dimensions to consider (Fig. 1). The paper introduces a few new concepts to assess a waterway condition (hazard intensity, value intensity and need intensity) and explores how this might be measured and visualised. The paper also goes into more detail about the Living Waterways V2 - Triage and Strategic Planning approaches.

\section{APPLYING THE MEDICAL MODEL TO WATERWAY HEALTH}

There is much to be learned from other fields of practice and the way that difficult issues are tackled. Key processes from the medical approach to health can be equally applied to waterway health management. Medical teams will often undertake the following steps to assess and treat a patient:

Step 1: Condition assessment

Step 2: Diagnosis

Step 3: Medication options

Step 4: Treatment plan

Step 5: Metrics

Step 6: Prognosis

Step 7: Monitoring (what is the current 'health' status?)

(what is causing ill 'health'?)

(what 'treatment' options are available?)

(what is the 'treatment strategy'?)

(what are the 'metrics' of success?)

(what will happen in future?)

(what is the periodic review and adaptation plan?)

The same diagnosis and treatment approach can be applied to 'waterway health'. Feedback from the stormwater industry [1] suggests that current stormwater regulations fail to manage the complexity and ignores the bigger picture. It can misdiagnose the correct ailments affecting the waterway and jumps straight to one particular type of treatment solution (e.g. bioretention basins). The medical equivalent would be to prescribe every patient the same dose of a particular medicine (e.g. ibuprofen). While this approach may be equitable, it does not cater for what the patient actually needs and does not make the most efficient use of resources.

THREATS

VALUES

GOALS

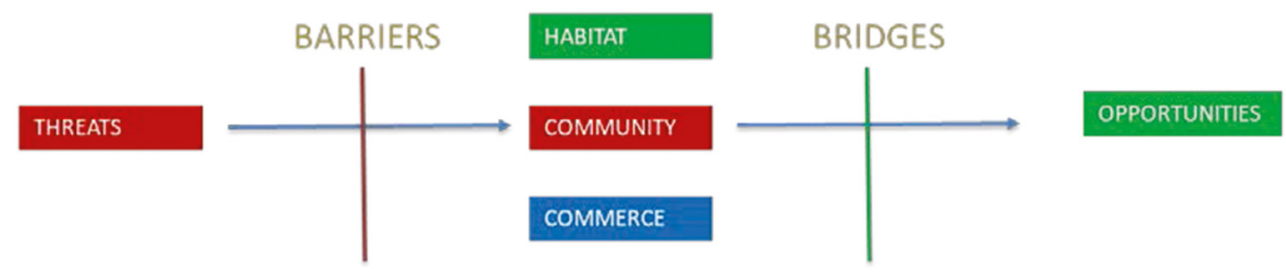

Figure 1: Value management framework. 


\section{STEP 1: CATCHMENT CONDITION ASSESSMENT}

\subsection{Using multidimensional analysis}

The current 'one-size-fits-all' approach to stormwater treatment was initiated to ensure equity across the state. However, the hazards, values and needs are not spread homogenously across a catchment, and typically, this approach ends in one-dimensional solutions that address neither the complete risk picture nor the potential co-benefits [3].

The following values management framework aims to assess the current value, assess potential hazards that could degrade waterway value and assess opportunities for increasing waterway value based on catchment needs. These three dimensions combine to form a diagnosis of the catchment condition and can assist in planning its potential treatment strategy and recovery pathway.

\subsection{Calculating value, hazard and need intensities}

Waterway value is subjective and can mean different things to different people; nevertheless, there have been numerous efforts to try and calculate and represent value; likewise, the hazard and need dimensions are also subject to much debate in the scientific community. Further information for South East Queensland regarding ecosystem and community values associated with water can be found at the following website: http://www.ecosystemservicesseq.com.au. Figure 2 is an example questionnaire that waterway managers can use to calculate value, hazard and need intensities. The value scoring has been based on the Healthy Land and Water Report Card for South East Queensland [4].

The elements and weightings of each item in the questionnaire will need to be adjusted according to local priorities. As new science comes to bear, weightings need to be further refined. It is acknowledged that adjusting the scoring and weighting is not an insignificant task and needs to be undertaken by a team of expert ecologists and environmental engineers. However, once this is undertaken, a sophisticated multidimensional analysis can be implemented with some confidence.

\subsection{Spatial analysis using the colour spectrum}

Spatial analysis is a critical tool to help waterway managers to direct money to where it is needed most. Intensity maps (heat maps) are already being used widely within the water industry to identify areas of high value and/or hazard and are able to spatially display the intensity of a given parameter. For example, in the flooding context, hazard maps can be created that indicate the peak flood depth and velocities across a flood plain. This can be especially useful for catchment managers who have vast areas to manage, and colour-coded visualisation will allow a manager to hone in on priority areas. This paper suggests a novel approach of using primary colours to represent the value, hazard and need dimensions which has a number of surprising results and benefits when colours are combined.

\subsection{How can the properties of colour and light assist?}

Colours naturally come with certain connotations and meanings: red means danger, green means go and light blue is calming. Cues from these associations can be made and a range of colour categories can be assembled to represent different risk and opportunity scenarios. 
Three primary colours, red, green and blue (RGB), are commonly used to create a whole spectrum of colours for electronic displays such as computer monitors and TVs. In this model, RGB are assigned to the hazard, value and need dimensions (respectively). Colour intensities can be automatically generated based on the results of the questionnaire (Fig. 2). The lower the colour intensity score (i.e. R, G or B value), the lower the parameter importance and the darker the resultant colour (Fig. 3). The key is to ensure that the total possible score from the questionnaire adds up to 250 points for each dimension. This will allow easy conversion into an RGB colour and provide ease of later analysis.

\subsection{Combining colour}

The addition of certain pairs of coloured light can create new colours; for example, red and green combine to form yellow, blue and green form cyan and red and blue form magenta. The combination of all three colours creates pure white light (Fig. 4). Combining colours using the RGB system is quick and easy to do and can be achieved in most Microsoft applications via custom colours (Fig. 5).

\subsection{Systems thinking}

To overcome the one-dimensional outcomes that are a result of the current stormwater regulations, we need to move to a system approach. This means that we need to understand how one variable may overlap, affect or influence another variable. In the risk management industry, these overlaps are referred to as 'critical vulnerabilities' [4]. It could also be referred to as a 'critical adjacency' which would also encapsulate key opportunities.

Hotspots Occur where high value assets coincide with high hazard sources and represent a key risk.

Coldspots Occur when a value deficiency occurs adjacent to high need and represents a key opportunity.

Once individual hazard, value and need intensities are determined throughout the catchment, then GIS layers can be overlain or better yet combined to determine these key priority areas. A modified version of a heat map can be created that allows display of many more dimensions on the same GIS layer than traditional approaches. There is no need for the planner to flick between many different layers to identify hotspots and coldspots.

\section{STEP 2: DIAGNOSIS PHASE}

Triage in the medical model usually assigns a colour ticket to each patient to designate the treatment priority. By taking this one step further and using a colour spectrum, we allow a myriad of different intervention options (Table 1 and Fig. 6).

Table 1 outlines a list of different scenarios and possible combinations from the RGB analysis. This in turn can be linked to management interventions (refer Section 5) and policy settings that apply to developments within a catchment. It should be noted that there are certain scenarios that may occur only very rarely in real life; however, this analysis exposes the potential theoretical range of values. 

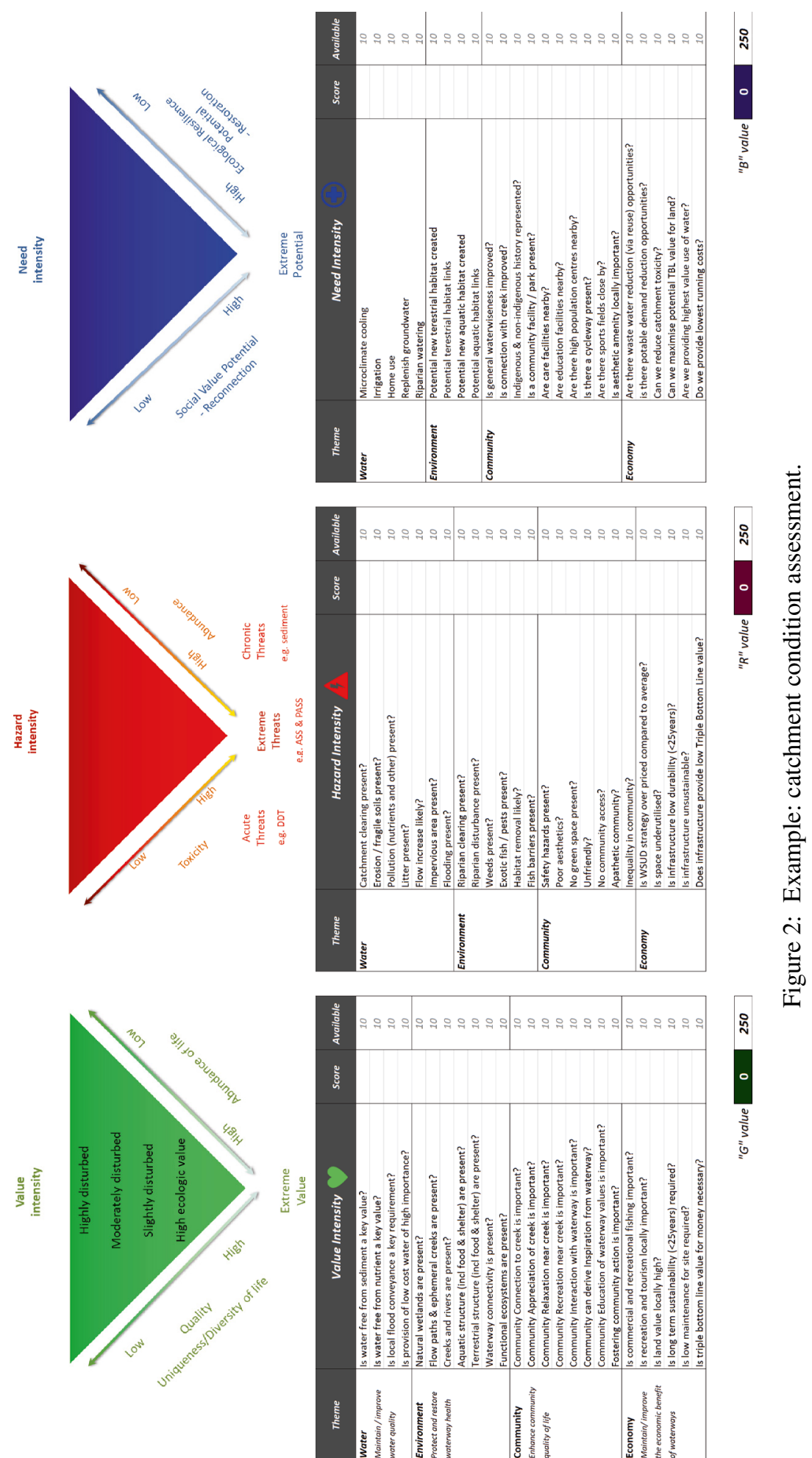


\section{Colour Reference Chart}

\begin{tabular}{|c|c|c|}
\hline G value & R value & B value \\
\hline 250 & 250 & 250 \\
225 & 225 & 225 \\
200 & 200 & 200 \\
175 & 175 & 175 \\
150 & 150 & 150 \\
125 & 125 & 125 \\
100 & 100 & 100 \\
75 & 75 & 75 \\
50 & 50 & 50 \\
25 & 25 & 25 \\
\hline
\end{tabular}

Figure 3: Colour intensity chart.

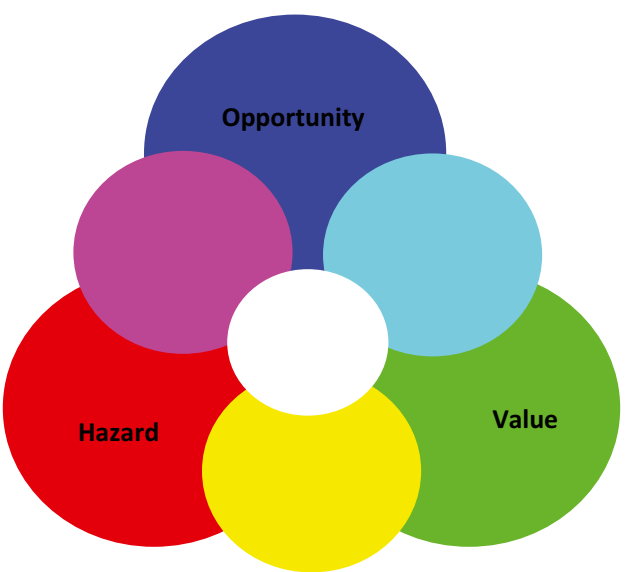

Figure 4: Colour combinations.

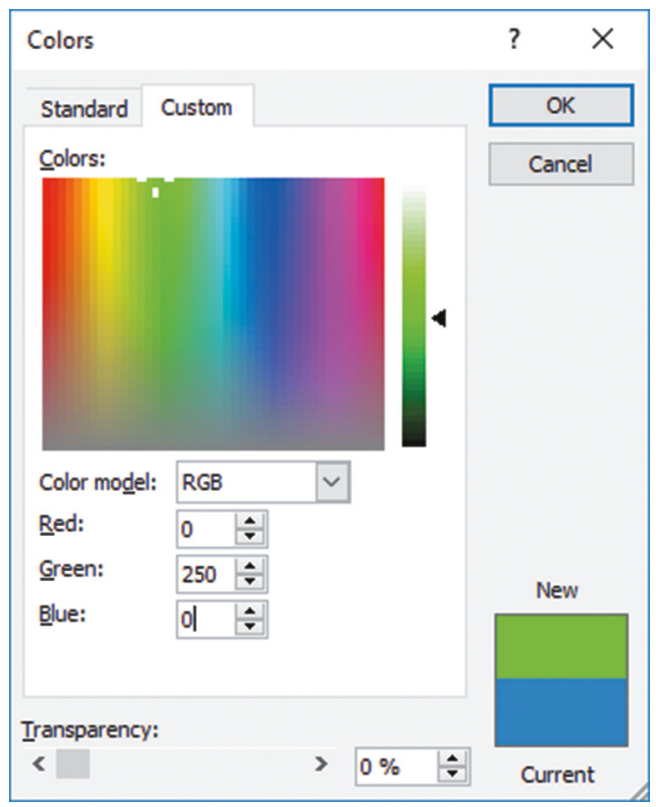

Figure 5: Colour addition. 


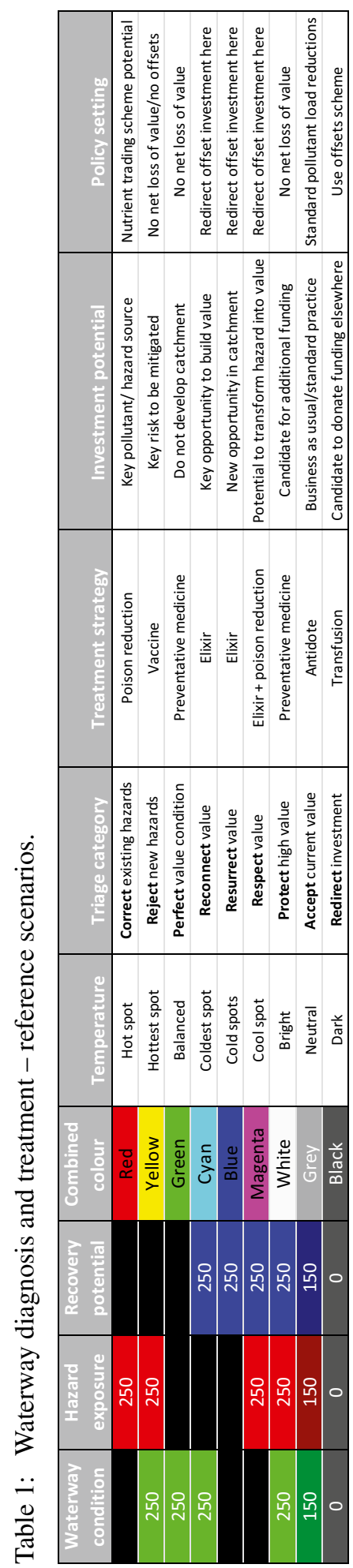




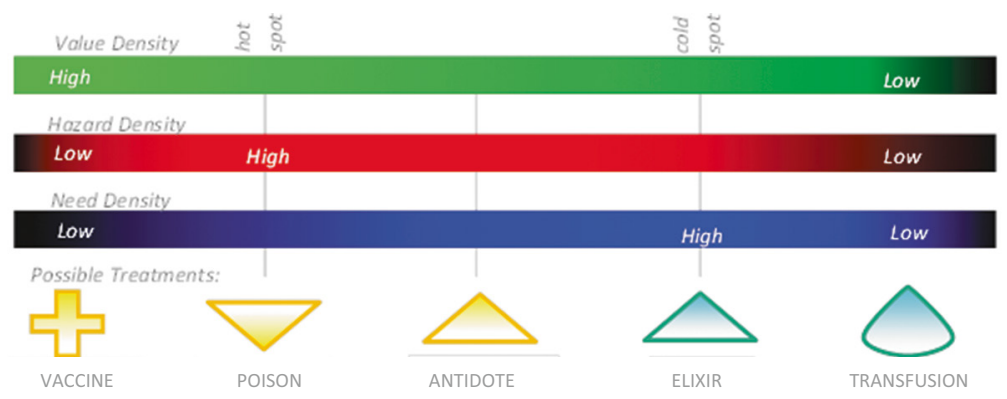

Figure 6: Waterway/catchment treatment options based on catchment condition.

\section{STEP 3: WATERWAY TREATMENT OPTIONS (MEDICATIONS)}

\section{Preventative medicine - prevent development in the first instance}

Prevention is often cited as the best cure. One option to preserve waterway value at the original (maximum) level is to not permit development to occur at all. This option is probably best applied in key pristine catchments in the strategic growth plan for a local area.

Vaccines - change the way development occurs

To permit development and still maintain waterway value at current levels requires a vaccine that fundamentally changes the DNA of development. This can be seen as an ultimate goal and relies on building typologies and roads being essentially invisible and replicating natural conditions. We are a fair way off implementation of this goal at the moment although green technologies such as green roofs, permeable roads and rainwater tanks will take us most of the way there.

Poisons - reduce the toxicity of the catchment

Poison reduction programmes rely on broadscale behaviour change such as elimination of pesticide, fertiliser, animal faeces and surfactants (from car washing) in stormwater runoff. Their focus can also be on reduced pollutant generation through erosion control (cover management) rather than sedimentation treatment. Their initiation can be via legal changes such as the single-use plastic ban or via good environmental design such as fencing off waterways to prevent disturbance.

Antidotes - treat waterway pollution

Present policy is steering the stormwater industry towards treatment (antidote) options including bioretention basins and Gross Pollutant Traps (GPTs). While this technology definitely has its place, it is noted that for antidotes to be effective, they need a hazard to be generated in the first place and they do not actually increase the value of the waterway above the baseline, and they only arrest/slow potential degradation.

Elixirs - enhance waterway value

Elixirs are management actions that can improve waterway values and can include bank stabilisation, restoration of fish connectivity as well as community stewardship projects that can help promote the active resilience of a waterway. A good source of 
funding for elixirs is via offsets (transfusions); this will enable transfer of resources and effort to where it can make the biggest impact.

Transfusions - transfer investment from one waterway to another

Much like blood transfusions, the transfer of resources from one segment of low value/low potential creek to a low value/high potential creek can maximise the net impact of each investment dollar. The transference will weaken the donor creek; however; the value gain from the transfer far exceeds the discomfort experienced by the donor creek and can potentially prevent catastrophic fish kills, for example, in the recipient creek.

Vitamins - minimum required maintenance

Vitamins can help maintain health and are appropriate for all health categories. In the same way, general day-to-day maintenance is required for nearly every waterway. Maintenance actions include unblocking culverts, litter collection, weeding, etc. This represents the minimum level of investment into a given waterway.

\section{STEP 4: TREATMENT STRATEGY}

\subsection{Waterway triage}

Environmental projects are often poorly funded by governments who often divert funds into hospitals, schools and roads often for good reason. In order to maximise the potential impact of the available funding for waterways, there needs to be a catchment-wide strategy in place to distribute funding across the catchment. So taking the medical approach one step further, we can use triage to apply a prioritisation filter to maximise the potential impact when resources are limited [2]. Applying the same theory to waterway management, we can direct scant resources to where they will make the biggest difference.

Instead of focusing on patients (i.e. rivers) that will survive regardless of treatment or patients (i.e. rivers) that will die regardless of treatment, effort is focused on actions that will arrest a spiral out of control and other life-saving operations. Recent studies have suggested that $90 \%$ of pollution can occur from $10 \%$ of the catchment $10 \%$ of the time [5]. This really highlights the need to prioritise our interventions.

Strategic funding will enable a balanced portfolio of treatments to be selected with risk investment aiming to protect existing value and opportunity investment aiming to enhance or create new value (Fig. 7).

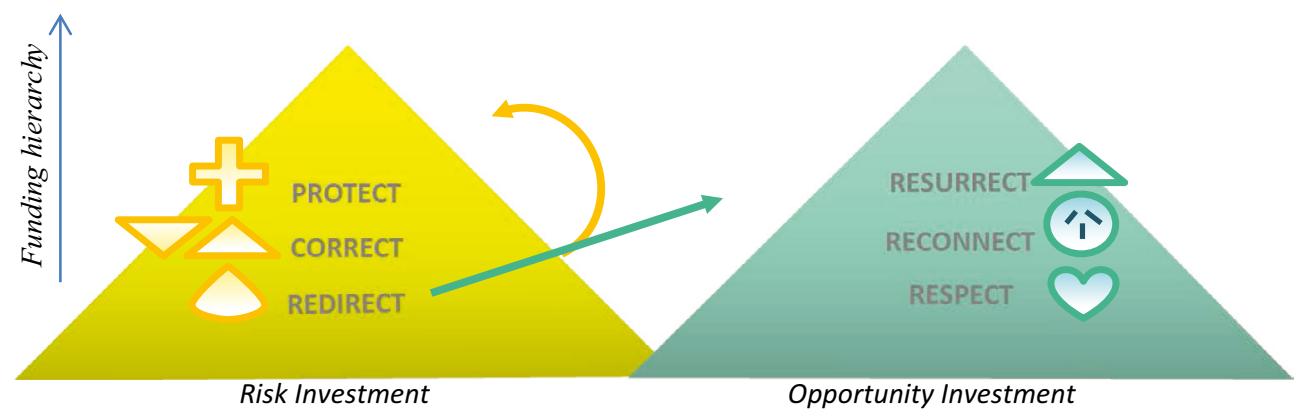

Figure 7: Prioritisation framework. 


\subsection{Risk investment - waterway protection}

The risk investment hierarchy more or less follows the standard hazard control hierarchy (i.e. avoid, mitigate, offset). Emphasis should be on projects that avoid impact before mitigation and offsets are employed. The 'Protect' and 'Correct' strategies have previously been discussed in detail in the previous work by Browning [2]. Note that these philosophies need to be tested on a case-by-case basis and cannot be applied in a blanket fashion.

\subsection{Opportunity investment - waterway enhancement}

For areas with low hazard, value and need, the 'Redirect' option should ideally be selected (i.e. transfusions or offsets) [6]. This triggers the transfer of resources to potential opportunities (coldspots) or waterway protection programmes (hotspots) via an offset framework. This strategy overcomes the need for equity and cost sharing but redistributes the benefit where it is needed most and greatly expands the possible return on investment [4]. Three examples of projects to enhance waterway value using the opportunity investment framework (i.e. Resurrect, Reconnect and Respect) are detailed in the following section.

\section{Resurrect Values - Small Creek}

Ipswich City Council has been investing significant sums of money to re-naturalise a creek at Raceview, QLD. The project fulfils a number of key habitat and community needs including:

- Removal of a concrete drain and replacement with a naturalised creek

- Provides treatment of stormwater via litter collection and nutrient filtration

- Extends habitat corridor up from Deebing Creek

- Reconnects to the indigenous heritage - weaving circle/yarning circle

- Allows for flooding/slows velocities allowing for settling and reduced scour

- It has been funded in part via offsets

- A co-design approach to inspire community ownership and long-term maintenance

- A bike path connecting to the local school encourages active transport

This project represents a significant increase in waterway value from the existing concrete drain and represents a 'resurrection' of an urban waterway moving it back towards predevelopment conditions.

\section{Reconnect Values - Davidson Street}

This project is a much smaller scale than Small Creek, and the main difference is that it builds on an existing creek with fairly high value but with key community needs. The project acknowledges that further increase in waterway value is not likely without community backing. Its main aim therefore is to reconnect the community to the creek and inspire community action and waterway stewardship. Features of this project include:

- Weed management and revegetation

- Stormwater low flow filtering via a soakage basin

- A co-design approach to inspire community ownership and long-term maintenance

- Nature play - reconnect children to nature 
- Education initiatives - inspire long-term stewardship

- Increased amenity capitalising on natural beauty

- Habitat enhancement

- Artistic sculptures and attractors - to encourage pride of place

This project will represent a moderate increase in habitat value in the short term; in the long term, it aims to invest in the social capital and stewardship of the local community.

\section{Respect Values - Go2Zone}

This project initiated by Healthy Land and Water aims to modify the behaviour of the general public by encouraging disuse of single-use plastic bottles, a major contributor to waterway pollution. The project has:

- An educational component regarding litter prevention plastic minimisation

- Community service - provision of pure chilled water

- Revenue positive - income received from stations can be reinvested into catchment enhancement projects

There are many other ways that community respect of waterways can be encouraged including container deposit schemes, single-use plastic bans, washing cars on lawns as well as stewardship programmes such as weeding and revegetation of waterways. These programmes all require funding, and stormwater offsets can be a source of money.

\section{STEP 5: METRICS - RECALIBRATING THE CONCEPT OF VALUE FOR MONEY}

People will be familiar with the term 'bang for buck'. This is commonly interpreted by the stormwater industry as removing the most tonnes of sediment per dollar possible (Refer CBA [2]). While this may lead to large volumes of sediment removal, depending upon where you intervene in the catchment, there may be little improvement in waterway biodiversity, and this is a perfect example of inefficient one-dimensional problem solving. The missing link in the cost/benefit analysis for many projects is the impact on ecology or ecological return on investment. This paper calls for expansion of the 'bang for buck' idea and suggests some other metrics to complete the picture (Fig. 8).

The Living Waterways Framework (LWF) [7, 8] introduces the quadruple bottom line for measuring the value of urban waterways. Often, many of the important aspects of why a waterway is important are intangible and are not easily measured. For example, how does one measure how relaxing a stretch of waterway is? Furthermore, how do we put a dollar value to that relaxation? But for local residents, these green spaces can potentially have an impact on mental well-being as is indicated by recent studies [9] and are a vital part of the landscape. These intangibles are often externalised and excluded from economic analysis and do not factor into the economic valuation of a project. This needs to change, and WbD's LWF goes part way towards recognising these intangible benefits.

For each quadrant of the quadruple bottom line, key sub-elements are evaluated and design responses (i.e. treatments) can then be implemented to either protect or enhance value as discussed previously. 


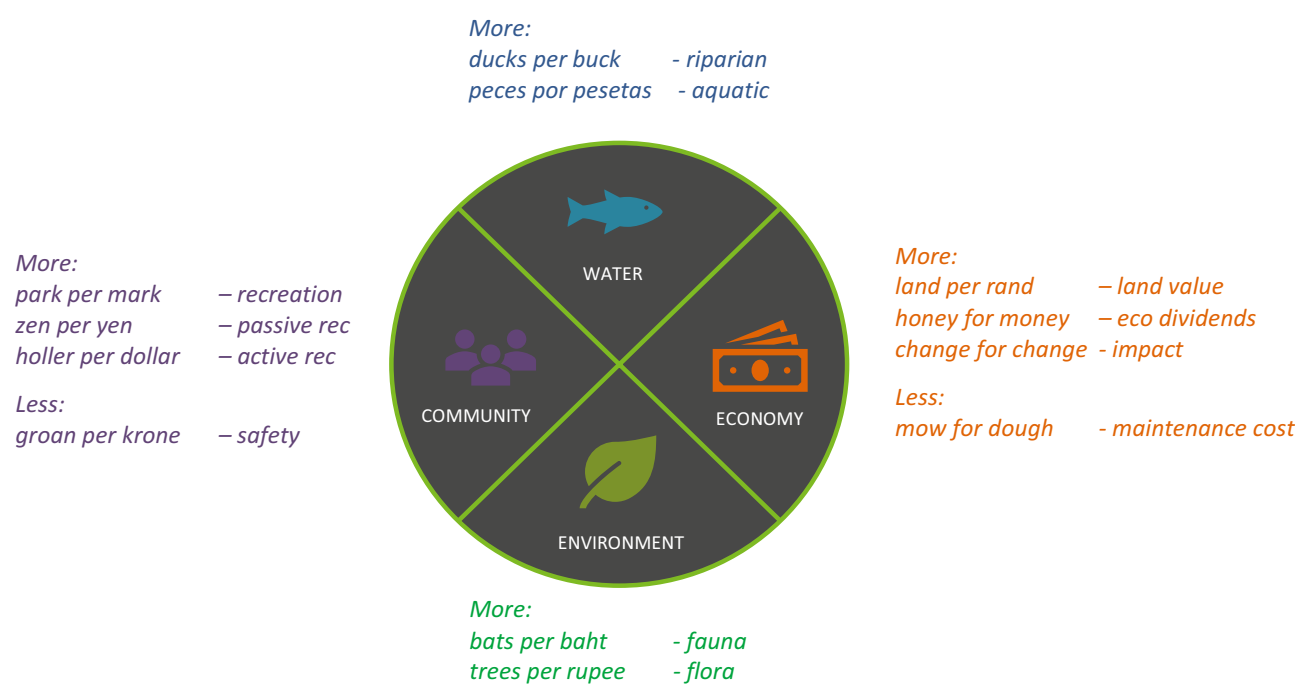

Figure 8: The quadruple bottom line - how many per penny?

\section{STEP 6: PROGNOSIS - PREDICTED RECOVERY TRAJECTORY}

It is important to understand the prognosis of a given waterway. This will help waterway managers to prioritise investments according to recovery potential and strategies can also be adapted to suit. The newest version of the LWF has an online tool for calculating the nominal waterway value trajectory following intervention (Fig. 9) (refer Strategic Planning Module [8]). A starting value is calculated based on the value questionnaire (Fig. 2). Four percentage points are deducted for each poison present in the catchment. This represents the worst case scenario, i.e. without intervention. Remedies (interventions) are then applied, and the waterway value is potentially increased.

This simple tool will help users to visualise the impact of certain design decisions may have on value trajectories. While this may seem self-evident, there is a common myth that installation of a bioretention basin (i.e. an antidote) will be a panacea and restore waterway health to predevelopment levels. While bioretention is definitely a part of the solution, it only works to partially neutralise some pollutants and cannot hope to fully preserve waterway value [10].

Understanding these concepts is crucial in shifting practitioners to invest in more preventative measures to protect waterway health instead of mitigation measures.

Figure 10 can be seen as a quasi-stock price for a waterway and shows how waterway value can respond to different interventions. It is noted that risk mitigation can only stabilise the value, whereas opportunity intervention can restore waterway value. Ideally, there needs to be a mix of risk and opportunity investment.

Some analysis needs to be undertaken to calculate necessary level of investment in the catchment in order to achieve the desired long-term waterway value target. This will be the focus of future investigation for $\mathrm{WbD}$.

\section{STEP 7: MONITORING - REVIEW AND ADAPTIVE MANAGEMENT}

In the medical model, the practitioner will often recommend further tests and checks to monitor the health of a patient. So too with waterway health management, there is need to monitor 


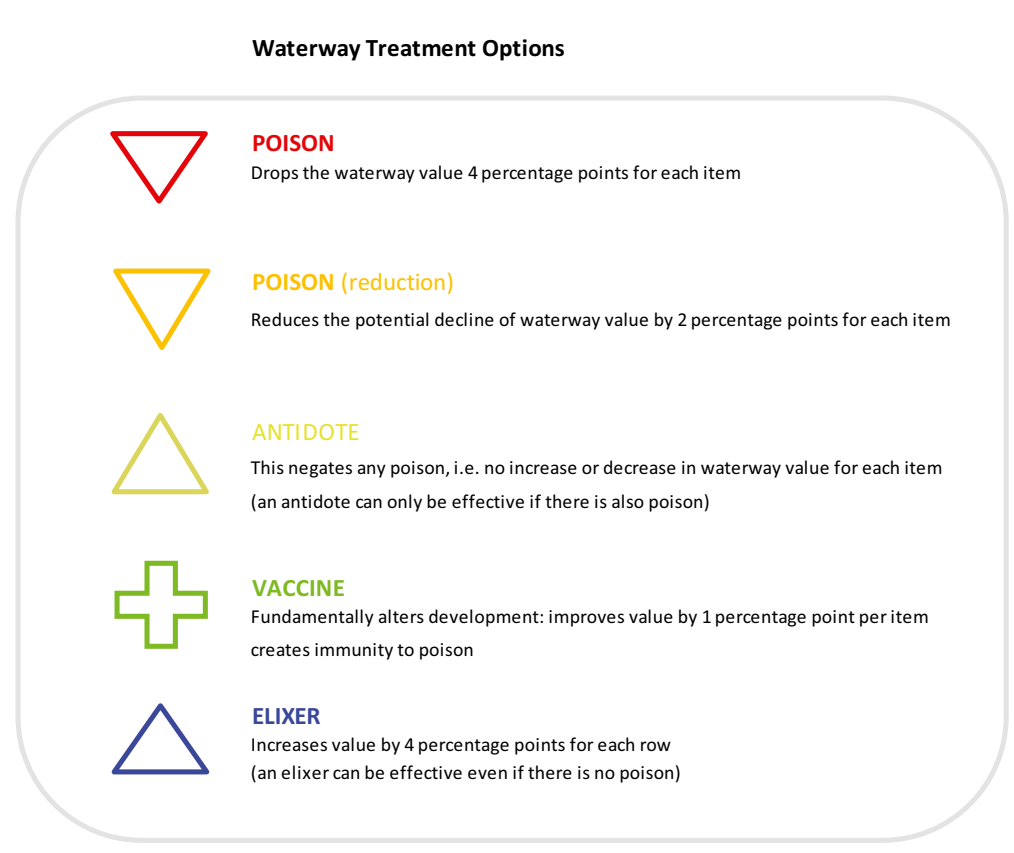

Value Trajectory Module
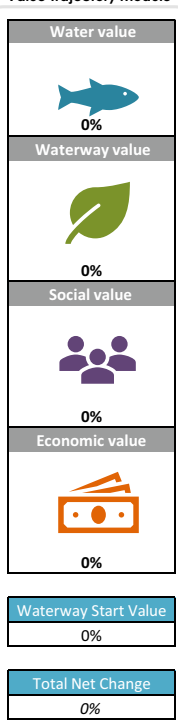

\begin{tabular}{|c|}
\hline Waterway End Value \\
\hline $0 \%$ \\
\hline
\end{tabular}

Figure 9: The living waterways framework: strategic planning module.

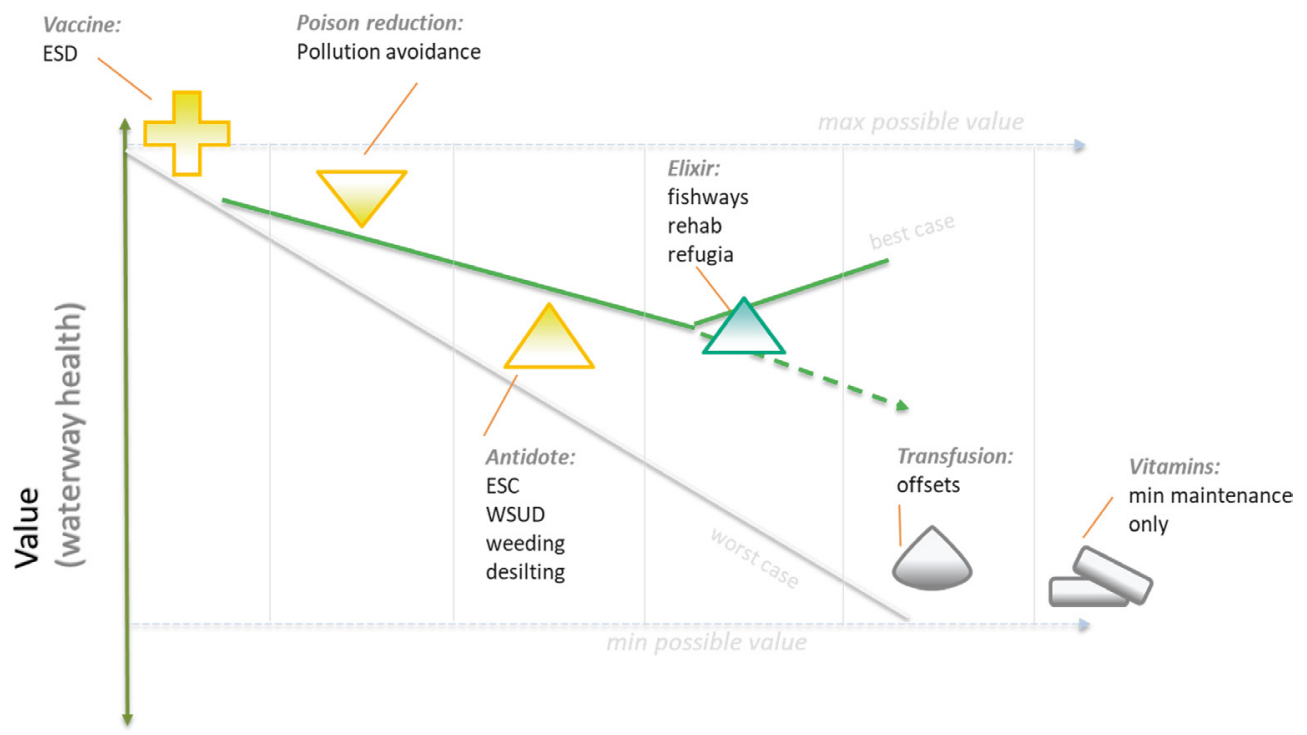

Figure 10: Predicted waterway value response to intervention. 
the progress towards targets and adapt management intervention accordingly [11]. This has been discussed in the previous work [2] and is a fundamental part of resilience planning.

Monitoring the risk landscape will allow us to respond to changes in the environment. It will also allow us to gage the effectiveness of our effort to protect our values. This leads us to examine two more important factors that influence project successes: risk effectiveness and implementation effectiveness.

\subsection{Risk effectiveness}

For a risk to actually be 'effective' and cause harm to a value requires a whole chain of events to occur: the hazard needs to be intense enough, it needs to be of the right frequency and duration, it needs to be proximal and connected to the value, the value needs to be susceptible, etc. [2]. We can categorise and rank risks according to their effectiveness, and this will allow us to concentrate efforts on managing the most effective risks (Fig. 11).

\subsection{Implementation effectiveness}

It is acknowledged that for a risk mitigation or opportunity implementation to be successful, it relies on a coordinated effort by a range of individuals working towards a common goal. For example, building a stormwater treatment wetland first requires legislation and then planning, design, construction and approval. This phenomenon can be likened to the risk effectiveness described above; it requires a sequence or chain of events to be put in place. For further information regarding the 'implementation hierarchy' and the 'risk pathway hierarchy', refer to [2].

\section{COMBINING THE SEVEN HIERARCHIES}

Work to date has developed seven possible waterway management hierarchies:

- Value (Green)

- Hazard (Red)

- Need (Blue)

- Risk management (Yellow)

Risk Pathway \&

Effectiveness

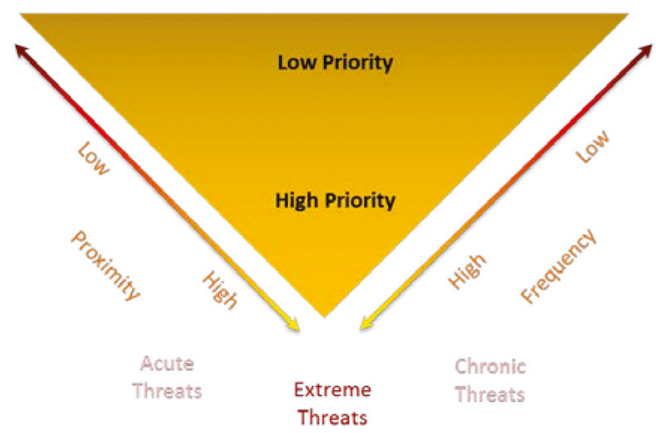

Implementation Effectiveness

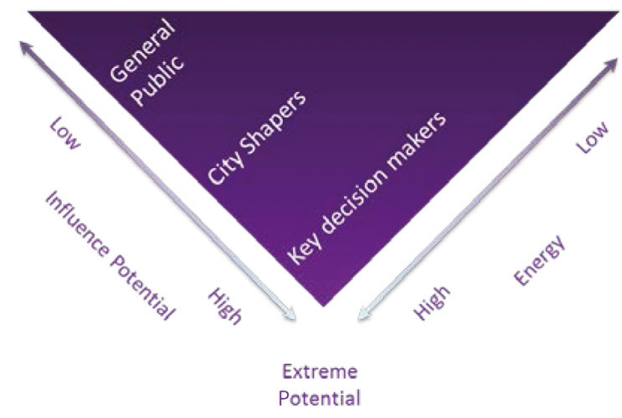

Figure 11: Risk pathway and implementation hierarchies. 
- Opportunity management (Cyan)

- Risk pathway (Orange)

- Implementation (Purple)

These seven hierarchies can be combined into a single model (Fig. 12). This tool allows a waterway manager to form a range of available risk/opportunity strategies that correlate with the colour spectrum. To assist with priorities, the most important elements are located at the centre of the circle (i.e. the short-term priority) and the elements at the outer ring form the long-term priority.

If considered separately, these hierarchies would represent sound management practice; however, by combining the hierarchies into the one model, we can zero in on the highest priority projects maximising the ecological and social return on investment.

\section{CONCLUSIONS}

WbD has surveyed industry stakeholders regarding the key issues with current stormwater policy in Queensland. The key issues identified included the need for more holistic assessment of risks and opportunities in the catchment and the need to prioritise funding to maximise return on investment.

\section{Value}

Density

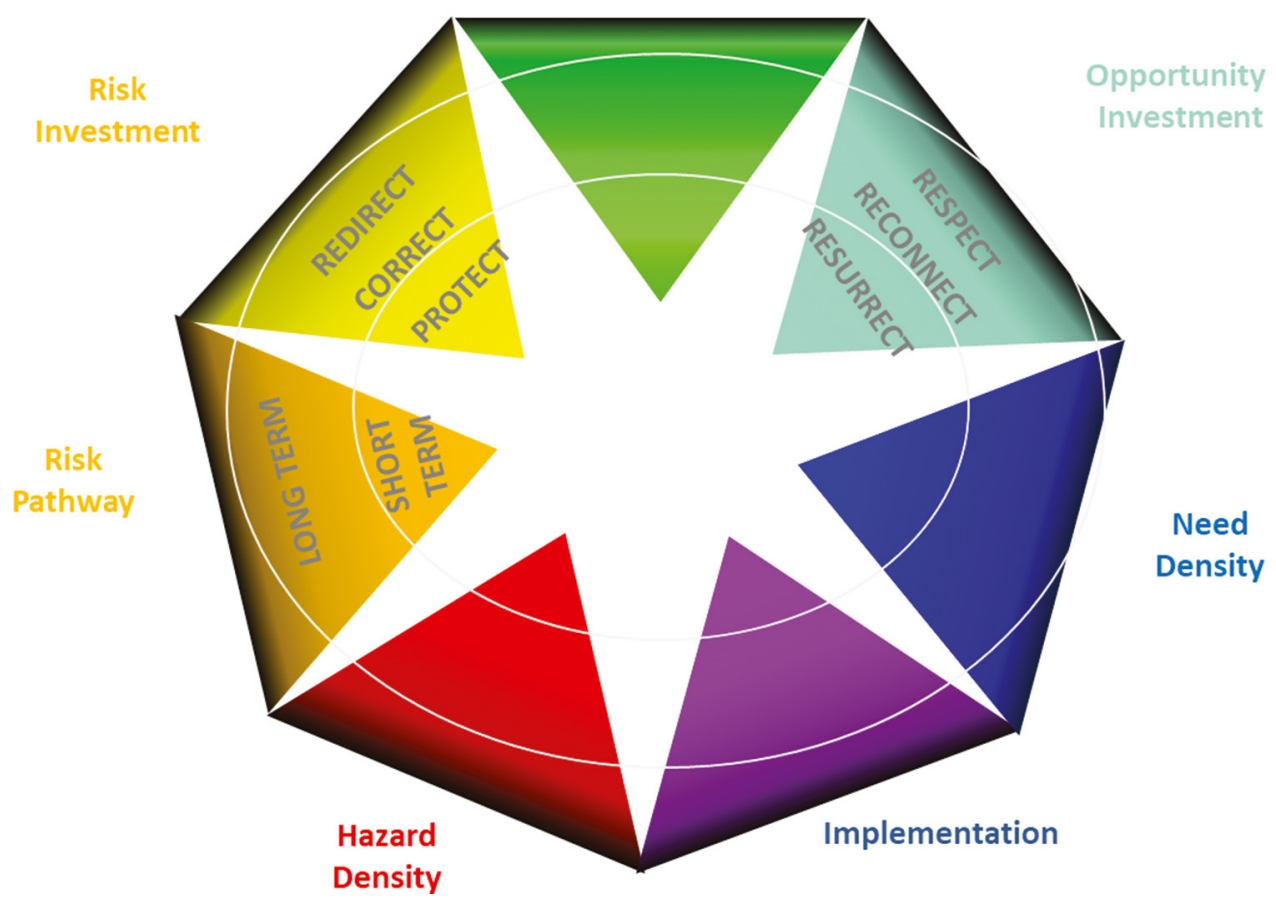

Figure 12: Multidimensional prioritisation hierarchy. 
This paper has adopted key approaches from the field of medicine to diagnose, prioritise and create a treatment plan. It has also outlined a way for multidimensional assessment of waterway condition; this can be visualised using primary colours (representing value, hazard and need intensity). Addition of these primary colours can then be used to diagnose a catchment and to recommend a treatment approach and help identify priorities. WbD has created the LWF which incorporates these new tools and allows practitioners the flexibility needed to adapt their management intervention to the local context. Other benefits of this approach include maximising the potential environmental and social return of each investment dollar.

$\mathrm{WbD}$ is currently reviewing the progress of Water-Sensitive Urban Design (WSUD) practice to date and has been reflecting on lessons learned. In conjunction with The Department of Environment and Science and Alluvium, the team will release a discussion paper [10] with recommendations for adaptation and refinement of the current stormwater regulations in QLD. This work represents a critical stepping stone towards delivering truly water-sensitive cities.

\section{ACKNOWLEDGEMENTS}

Thanks and acknowledgement go to Healthy Land and Water and the Water by Design programme. Their supportive environment and encouragement to challenge the status quo made this paper possible. A special thank you to the Qld Department of Environment and Science for Sponsoring the Water By Design Program.

Thanks must go especially to my colleagues: Dr Andrew O’Neill, Adrian Crocetti, Dr Paul Maxwell, Rachael Nasplezes and Karen Toms. Special thanks go to Dr Emily Saeck for kindly lending her time in reviewing this paper.

Thanks also go to the mentors and thought provokers throughout my career: Dr Peter Breen, Malcolm Eadie, Sally Boer, Kim Markwell, Dr Courtney Henderson, Tony Webber, Alan Hoban, Brad Dalrymple, Paul Dubowski, Shaun Leinster, Andrew Cook, Brad Dines, Richard Robinson, Luke Galea, Chris Manning, Matt Moore, John Gunn, Sarah Choudhury and Trina Morris.

Jack Mullaly's 'That's like WSUD' blogs [ideanthro.com] were partial inspiration for this paper.

\section{REFERENCES}

[1] Skull, S., et al., State of the Streams, Water by Design, available at https://hlw.org.au/ resources/, 2014 and 2017.

[2] Browning, G.D., Let's Get Our Priorities Straight, WIT Transactions on Ecology and the Environment, Vol. 228, WIT Press: UK, 2018, ISSN 17433541.

[3] Browning, G.D., Are Trade-Offs Acceptable or Are We Accepting Defeat?, 9ASM August 2018, Hobart, Australia.

[4] Maxwell, P., et al., Report Card: Methods Manual, Healthy Land and Water, 2017.

[5] McClain, M.E., et al., Biogeochemical Hot Spots and Hot Moments at the Interface of Terrestrial and Aquatic Ecosystems, Vol. 6, Issue 4, Ecosystems, available at https:// link.springer.com/article/10.1007/s10021-003-0161-9, June 2003.

[6] Gooding, K., et al., Off Site Stormwater Quality Solutions, Water by Design, 2014

[7] Gooding, K., et al., Living Waterways Framework, Water by Design, available at https://hlw.org.au/resources/, 2014.

[8] Browning, G., et al., Living Waterways Framework, Version 2, Water by Design, available at https://livingwaterways.com.au/, 2018. 
[9] Lee, A.K.A. \& Maheswaran, R., The health benefits of urban green spaces - a review of the evidence. Journal of Public Health, 33(2), pp. 212-222, 2010.

[10] Weber, T., et al., Stormwater Management Design Objectives, Alluvium 2018.

[11] O’Neill, A., Weber, T. \& Browning, G., Were load based objectives a necessary mistake to progress water sensitive urban design?, 9ASM August 2018, Hobart, Australia. 